\title{
Genetic Aspects of Celiac Disease in Association with Pancreatic Tumors
}

\author{
Pavel Procházka ${ }^{1,2, *}$ \\ ${ }^{1}$ Department of the Molecular Biology of Cancer, Institute of Experimental Medicine AS CR, Prague, Czech Republic \\ ${ }^{2}$ Institute of Biology and Medical Genetics, First Faculty of Medicine Charles University, Prague, Czech Republic \\ *Corresponding author: proch.pavel@gmail.com
}

Received July 31, 2014; Revised September 10, 2014; Accepted September 17, 2014

\begin{abstract}
Celiac disease stands out as a major health problem with a frequent association with many other disorders. Studies show an increased risk of developing pancreatitis and after that pancreatic cancer in patients with celiac disease. A frequent occurrence and a remarkably close association with the HLA-DQ2 and/or DQ8 gene loci represent main genetic characteristic of celiac disease. A particular association was found with chromosome 15q26 and 6q21-22. On the other hand pancreatic tumors are known for associations with CTNNB1, VHL, CDKN2A, KRAS, TP53, RNF43, SMAD4, GNAS, PRSS1, ATM, BRCA1, BRCA2, PALB2, STK11 and hereditary non-polyposis colorectal cancer syndrome genes. Recent genetic mapping suggests that a large field of opportunities exists for better understanding of both diseases.
\end{abstract}

Keywords: celiac disease, pancreatic tumors, HLA-DQ2 gene locus, DQ8 gene locus, KRAS, BRCA1/2

Cite This Article: Pavel Procházka, "Genetic Aspects of Celiac Disease in Association with Pancreatic Tumors.” International Journal of Celiac Disease, vol. 2, no. 3 (2014): 93-96. doi: 10.12691/ijcd-2-3-6.

\section{Introduction}

Since the fifties of the last century, we have known the term celiac lesion localized in the proximal small intestine. The primary findings were mucosal inflammation, crypt hyperplasia, and villous atrophy. With the development of peroral biopsy, it became apparent that celiac disease and adult nontropicalsprue shared the same features and pathogenesis. When unrecognized and untreated, celiac disease is associated with increased mortality. Celiac disease is frequently associated with many other disorders such as dermatitis herpetiformis, Down syndrome, selective IgA deficiency, and other conditions which have autoimmune features such as type 1 diabetes mellitus, thyroid disease, and liver disease. Patients with celiac disease (and their families) may also be more likely to have atopic dermatitis compared with the general population, although the prevalence of other allergies is not increased [1]. Large database studies have described an increased risk of pancreatitis (both acute and chronic) in patients with celiac disease [2,3]. Further studies are needed to clarify the strength of the association and potential mechanisms that underlie it. In the present review I would like to give an overview about the genetic aspects of Celiac disease and pancreatic diseases particularly pancreatic tumors.

\section{Genetic Aspects of Celiac Disease in Association with Pancreatic Cancer}

\subsection{Celiac Disease and Pancreatitis}

Is there any connection between Celiac Disease and Pancreatic disease? Sadr-Azodi at al. find an increased risk of developing pancreatitis in patients with celiac disease. In the study authors identified patients with celiac disease who were later diagnosed with pancreatitis. Patients with celiac disease had an almost 3-fold increase in risk of developing pancreatitis, compared with the general population, a hazards ratio (HR) of 1.9 in acute pancreatitis and an HR of 3.3 in chronic pancreatitis [3]. Every year are published new advances to further elucidate the influence of celiac disease on pancreatitis. The potential of artificial neural network (ANN) computer programs to aid diagnosis of chronic pancreatitis by endoscopic ultrasonography (EUS), detection of visceral pain as a predictor of pain relief from various treatments and prediction of pain relief from pancreatic surgery [4].

\subsection{Genetic Aspects of Celiac Disease}

Triggering factors of celiac disease are well understood. One of the most important environmental factors which can initiate the exacerbation of the symptoms of Celiac disease represents gluten and its related prolamins. The presence of gliadin, the alcohol-soluble fraction of gluten that contains the majority of toxic components, may initiate inappropriate innate and adaptive immune response leading to the development of Celiac disease. Recently, it has been demonstrated that gluten peptides can induce the generation of reactive oxygen species, which then stabilize hypoxia-inducible factor (HIF)- $1 \alpha$ by the inactivation of prolyl hydroxylases. The increased presence of mucosal HIF-1 $\alpha$ and its newly described 
regulator molecule Parkinson's disease 7 were demonstrated in patients with newly diagnosed Celiac disease suggesting their contribution to the pathomechanism of Celiac disease [5].

Celiac disease is characterized by a frequent intrafamilial occurrence and a remarkably close association with the HLA-DQ2 and/or DQ8 gene loci provide the basis of current understanding of celiac disease as an immune disorder that is triggered by an environmental agent gliadin in genetically predisposed individuals [6]. It has been estimated that the HLA contribution to the development of celiac disease among siblings is 36 percent. Thus, another gene or genes at an HLA-unlinked locus must also participate [7,8]. A particular association was found with chromosome 15q26, which contains a type 1 diabetes susceptibility locus [9], and possibly with 19p [10]. Studies in the Dutch, Finnish and Hungarian populations have revealed a locus on chromosome 6q21-22 conferring susceptibility to celiac disease and harbors multiple independent associations, some of which may implicate ubiquitin-pathways in celiac disease susceptibility [11]. HLA typing for DQ2 (DQA1*05; DQB1*02) and DQ8 (DQA1*03; DQB1*0302) may be useful in individuals with equivocal small bowel histologic findings since celiac disease is unlikely if neither is present [12]. Homozygosity for HLA DQ2 has been associated with an increased risk for celiac disease $[13,14]$ and enteropathy-associated T-cell lymphoma [13]. Non-HLA locus genes conferring risk for celiac disease have also been identified $[7,8]$ and an increasing number of non-HLA risk alleles has been associated with an increased risk of celiac disease [7]. A genome wide association study in large numbers of patients with celiac disease and matched controls from the United Kingdom, Italy, and Ireland identified a number of genes involved in controlling immune responses [15] (Table 1). In addition, type 1 diabetes and celiac disease share common genetic risk regions (including HLA-DQ). However, new identified genes or polymorphisms, even when taken together, contribute only 3 to 4 percent to the genetic risk for celiac disease, as compared with 30 to 40 percent for HLA-DQ2 or -DQ8.

Table 1. Genes with strong association for celiac disease

\begin{tabular}{|c|c|c|}
\hline Gene name & Gene location & Protein function \\
\hline RGS1 & $1 \mathrm{q} 31$ & a member of the regulator of G-protein signalling family \\
\hline IL1R1 & $2 q 12$ & a receptor for interleukin-1 alpha \\
\hline IL18R1 & $2 q 12$ & $\begin{array}{l}\text { a cytokine receptor that belongs to the interleukin } 1 \text { receptor } \\
\text { Family and binds interleukin } 18\end{array}$ \\
\hline IL18RAP & $2 q 12$ & a subunit of the receptor for interleukin 18 \\
\hline SLC9A4 & 2q12 & solute carrier \\
\hline CCR1 & 3p21 & a member of the beta chemokine receptor family \\
\hline CCR3 & 3p21 & a receptor for C-C type chemokines \\
\hline IL12A & $3 q 25$ & a subunit of a cytokine that acts on $\mathrm{T}$ and natural killer cells \\
\hline SCHIP1 & $3 q 25$ & schwannomin-interacting protein 1 \\
\hline$L P P$ & $3 q 28$ & a member of a subfamily of LIM domain proteins \\
\hline IL2 & $4 q 27$ & a secreted cytokine important for the proliferation of T and B lymphocytes \\
\hline IL21 & $4 q 27$ & a member of a family of cytokines with immunoregulatory activity \\
\hline TAGAP & $6 q 25$ & a function as a Rho GTPase-activating protein \\
\hline ATXN2 & $12 q 24$ & defects in the gene is the cause of spinocerebellar ataxia type 2 \\
\hline
\end{tabular}

\subsection{Genetic Aspects of Pancreatic Cancer}

The American Cancer Society estimates that 46,420 Americans will be diagnosed with Pancreatic Cancer and 39,590 will die in 2014. It makes this type of cancer one of the leading cause of cancer-related death. As has been demonstrated for colon cancer, the best hope for reducing the cancer mortality of pancreatic cancer lies in early diagnosis and treatment. Identification of early mutation in high risk genes could be one of nice ways. Recent advances highlight the enormous potential of molecularbased approaches as a tool for the detection of pathogenic gene mutations in the pancreas. One of them, a whole exome sequencing of well-characterized cyst-forming precursor lesions has defined the genes mutated in each of the different precursor lesions in the pancreas (Table 2). With these advances, everyone can easily envision that harmless cysts of the pancreas will be readily distinguishable from true precursor lesions in the near future [16].

Table 2. Genes mutated in the most common precursor and cystic lesions in the pancreas

\begin{tabular}{lll}
\hline Gene name & Gene location & Protein function \\
\hline CTNNB1 & $3 \mathrm{p} 21$ & adherens junctions \\
VHL & $3 \mathrm{p} 25.3$ & component of a protein complex that ubiquitinates and degradates \\
P16 / CDKN2A & $9 \mathrm{p} 21$ & HIF \\
KRAS & $12 \mathrm{p} 12$ & inhibition of CDK4 kinase \\
TP53 & $17 \mathrm{p} 13$ & signal transduction \\
RNF43 & $17 \mathrm{q} 22$ & regulation of expression, DNA repair, cell cycle arrest, apoptosis \\
SMAD4 & $18 \mathrm{q} 21$ & negative regulation of the Wnt signaling pathway \\
GNAS & $20 \mathrm{q} 13$ & signal transduction \\
\hline
\end{tabular}

KRAS (V-Ki-ras2 Kirsten rat sarcoma viral oncogene homolog) gene represents well-known and extensively studied genetic marker particularly in colorectal cancer.
KRAS mutations appear in 70-90\% of pancreatic cancers and are predominantly seen in codon 12, with rare exceptions seen in codons 13 and 61 [17]. KRAS 
mutations occur quite early before the onset of the actual cancer, in the precancerous stages, within lesions termed Pancreatic Intraepithelial Neoplasia [18]. Activated KRAS promotes the expansion of an endodermal stem/progenitor cell and blocks its differentiation and may thus uniquely contribute to the initiation of tumors in endodermallyderived tissues [19]. Retrospective analysis of results of clinical studies has shown that patients with metastatic colorectal cancer who have KRAS mutations do not respond to EGFR-targeted (epidermal growth factor receptor) therapeutics [20]. Recently published data show that mutational activation of phosphoinositide 3-kinase (PIK3CA), which commonly co-occurs with KRAS mutation, provides resistance to MEK inhibition through reactivation of AKT signaling. Tumors with both KRAS and PIK3CA mutations are thus unlikely to respond to the inhibition of the KRAS downstream MEK pathway alone but will require effective inhibition of both MEK and PIK3AC/AKT pathway signaling [21].

A number of cancer-causing genes has been described in association with an increased risk of pancreatic cancer (Table 3). Risk can be further refined when the causative genes are known and individuals can now undergo genetic testing to see whether they carry a familial pancreatic cancer susceptibility gene [16].

Table 3. Genes associated with familial pancreatic cancer

\begin{tabular}{lll}
\hline Gene name & Gene location & Protein function \\
\hline HNPCC5 / MSH6 & 2p16 & DNA mismatch repair \\
HNPCC1 / MSH2 & 2p22 & DNA mismatch repair \\
HNPCC3 / PMS1 & 2q31-q33 & DNA mismatch repair \\
HNPCC2 / MLH1 & $3 \mathrm{p} 21$ & DNA mismatch repair \\
HNPCC6 / TGFBR2 & $3 \mathrm{p} 22$ & TGFB receptor \\
HNPCC4 / PMS2 & $7 \mathrm{p} 22$ & DNA mismatch repair \\
PRSS1 & $7 \mathrm{q} 34$ & serine protease \\
p16 /CDKN2A & $9 \mathrm{p} 21$ & inhibition of CDK4 kinase \\
ATM & $11 \mathrm{q} 22-\mathrm{q} 23$ & serine/threonine kinase \\
BRCA2 & $13 q 12$ & double-strand DNA repair \\
HNPCC7 / MLH3 & $14 \mathrm{q} 24$ & DNA mismatch repair \\
PALB2 & 16p12 & tumor suppression, colocalize \\
BRCA1 & $17 \mathrm{q} 21$ & with BRCA2 \\
STK11 & $19 \mathrm{p} 13$ & double-strand DNA repair \\
\hline Abbreviatine/threonine kinase
\end{tabular}

Abbreviation: HNPCC, hereditary non-polyposis colorectal cancer.

Hereditary Breast and Ovarian Cancer is characterized by the presence of germline mutations in two cancer susceptibility genes, BRCA1 and BRCA2. Germline mutations in BRCA1 and especially BRCA2, are associated with an increased risk of pancreatic cancer [22,23,24]. BRCA2 mutations are found in as many as 12 to 17 percent of patients with familial pancreatic cancer [22,23]. Furthermore, an estimated 1.7 to 10 percent of patients of Ashkenazi Jewish origin who have pancreatic cancer carry a BRCA mutation, many of whom do not have a family history of typical BRCA-associated cancers [25,26]. Because of this, some have suggested that the diagnosis of pancreatic cancer in an Ashkenazi individual should prompt referral for BRCA testing [25]. Approximately 1 percent of non-BRCA1/BRCA2 deficient familial breast cancers are caused by germline defects in the $P A L B 2$ gene. The PALB2 protein binds with BRCA2 protein and stabilizes it in the nucleus; the BRCA2/PALB2 complex is part of the Fanconi Anemia DNA repair pathway that acts in double-stranded DNA repair. Mutations in the PALB2 gene confer an increased risk of both breast and pancreatic cancer. PALB2 mutations have been identified in 1 to 3 percent of familial pancreatic cancer kindreds [27,28,29]. The absolute magnitude of risk for pancreatic cancer in affected individuals is unknown.

Germline mutations in other genes, such as PRSS1 and STK11 are associated with Peutz-Jeghers syndrome (PJS), have been associated with an increased risk of pancreatic cancer. In individuals with PJS, the lifetime risk may be as high as 36 percent [30]. Autosomal dominant hereditary pancreatitis is most often associated with mutations in PRSS1. Rarely, autosomal-dominant-appearing hereditary pancreatitis is identified in a kindred that does not have an identifiable PRSS1 mutation. Hereditary pancreatitis is associated with a markedly increased risk of pancreatic cancer, although it accounts for a very small fraction of pancreatic cancer cases [31,32].

Interestingly, MLH1, MLH3, MSH2, MSH6, PMS1, PMS2and TGFBR2genes associated with the Lynch syndrome (HNPCC, hereditary non-polyposis colorectal cancer syndrome) are associated with pancreatic cancer as well. Except TGFBR2 gene coding the TGF receptor, all other HNPCC genes represent components of the DNA mismatch repair system [33].

Mutations in $C D K N 2 A$ characterize the familial atypical multiple-mole melanoma (FAMMM) syndrome, a disorder associated with multiple nevi, cutaneous and ocular malignant melanomas, as well as pancreatic cancers. A variant syndrome is described (the FAMMM-pancreatic carcinoma syndrome) in several families who have a specific 19-base-pair deletion in the p16 gene (the p16 Leiden mutation) and whose cumulative risk of pancreatic carcinoma by age 75 is as high as 17 percent [34].

\section{Conclusions}

Our understanding of the basic, genetic and clinical aspects of celiac disease increases every year. Lundin at al., recently designed current challenges in celiac disease as necessity of better case finding, distinguishing celiac disease from other gluten-sensitive conditions, better care and balanced use of resources [35]. Researchers have already described susceptibility loci and a number of genes associated with celiac disease with a well-known close association with the HLA-DQ2 and/or DQ8 genes. In the present comparison of genetic aspects of celiac disease and pancreatic cancer was not find a clear genetic relationship. On the other hand both disorders show genetic basic and both are characterized by many associated genes involved in the process of disease progression. Better understanding to this processes would be a way.

\section{Acknowledgements}

This work was supported by grant GA CR P301/12/1734.

\section{Statement of Competing Interests}

The author has no competing interests. 


\section{References}

[1] Ciacci, C., et al., Allergy prevalence in adult celiac disease. J Allergy ClinImmunol, 2004. 113(6): p. 1199-203.

[2] Ludvigsson, J.F., S.M. Montgomery, and A. Ekbom, Risk of pancreatitis in 14,000 individuals with celiac disease. ClinGastroenterolHepatol, 2007. 5(11): p. 1347-53.

[3] Sadr-Azodi, O., et al.. Patients with celiac disease have an increased risk for pancreatitis. ClinGastroenterolHepatol, 2012. 10(10): p. 1136-1142 e3.

[4] DiMagno, M.J. and E.P. DiMagno, Chronic pancreatitis. CurrOpinGastroenterol, 2013. 29(5): p. 531-6.

[5] Sziksz, E., et al., Coeliac Disease: From Triggering Factors to Treatment. International Journal of Celiac Disease, 2013. 1(1): p. 9-13.

[6] Schuppan, D., Current concepts of celiac disease pathogenesis. Gastroenterology, 2000. 119(1): p. 234-42.

[7] Romanos, J., et al., Analysis of HLA and non-HLA alleles can identify individuals at high risk for celiac disease. Gastroenterology, 2009. 137(3): p. 834-40, 840 e1-3.

[8] Trynka, G., et al., Coeliac disease-associated risk variants in TNFAIP3 and REL implicate altered NF-kappaBsignalling. Gut, 2009. 58(8): p. 1078-83.

[9] Susi, M., et al., Candidate gene region $15 q 26$ and genetic susceptibility to coeliac disease in Finnish families.Scand $\mathrm{J}$ Gastroenterol, 2001. 36(4): p. 372-4.

[10] Latiano, A., et al., Analysis of candidate genes on chromosomes $5 q$ and $19 p$ in celiac disease. J PediatrGastroenterolNutr, 2007. 45(2): p. 180-6.

[11] Einarsdottir, E., et al., Multiple independent variants in 6q21-22 associated with susceptibility to celiac disease in the Dutch, Finnish and Hungarian populations. Eur J Hum Genet, 2011. 19(6): p. 682-6.

[12] Kaukinen, K., et al., HLA-DQ typing in the diagnosis of celiac disease. Am J Gastroenterol, 2002.97(3): p. 695-9.

[13] Al-Toma, A., et al., Human leukocyte antigen-DQ2 homozygosity and the development of refractory celiac disease and enteropathyassociated T-cell lymphoma. ClinGastroenterolHepatol, 2006. 4(3): p. 315-9.

[14] Pietzak, M.M., et al., Stratifying risk for celiac disease in a large at-risk United States population by using HLA alleles. ClinGastroenterolHepatol, 2009. 7(9): p. 966-71.

[15] Hunt, K.A., et al., Newly identified genetic risk variants for celiac disease related to the immune response. Nat Genet, 2008. 40(4): p. 395-402.

[16] Lennon, A.M., et al., The Early Detection of Pancreatic Cancer: What Will It Take to Diagnose and Treat Curable Pancreatic Neoplasia? Cancer Res, 2014. 74(13): p. 3381-3389.

[17] Porta, M., et al., Cigarette smoking and K-ras mutations in pancreas, lung and colorectal adenocarcinomas: etiopathogenic similarities, differences and paradoxes. Mutat Res, 2009. 682(2-3): p. 83-93.
[18] Hruban, R.H., A. Maitra, and M. Goggins, Update on pancreatic intraepithelial neoplasia. Int J ClinExpPathol, 2008. 1(4): p. 30616.

[19] Quinlan, M.P., et al., Activated Kras, but not Hras or Nras, may initiate tumors of endodermal origin via stem cell expansion. Mol Cell Biol, 2008. 28(8): p. 2659-74.

[20] Allegra, C.J., et al., American Society of Clinical Oncology provisional clinical opinion: testing for KRAS gene mutations in patients with metastatic colorectal carcinoma to predict response to anti-epidermal growth factor receptor monoclonal antibody therapy. J ClinOncol, 2009. 27(12): p. 2091-6.

[21] Halilovic, E., et al., PIK3CA mutation uncouples tumor growth and cyclin D1 regulation from MEK/ERK and mutant KRAS signaling. Cancer Res, 2010. 70(17): p. 6804-14.

[22] Murphy, K.M., et al., Evaluation of candidate genes MAP2K4, $M A D H 4, A C V R 1 B$, and BRCA2 in familial pancreatic cancer: deleterious BRCA2 mutations in 17\%. Cancer Res, 2002. 62(13): p. 3789-93.

[23] Hahn, S.A., et al., BRCA2 germline mutations in familial pancreatic carcinoma. J Natl Cancer Inst, 2003. 95(3): p. 214-21.

[24] Iqbal, J., et al., The incidence of pancreatic cancer in BRCA1 and BRCA2 mutation carriers. Br J Cancer, 2012. 107(12): p. 2005-9.

[25] Ferrone, C.R., et al., BRCA germline mutations in Jewish patients with pancreatic adenocarcinoma. J ClinOncol, 2009. 27(3): p. 433-8.

[26] Lal, G., et al., Inherited predisposition to pancreatic adenocarcinoma: role of family history and germ-line p16, BRCA1, and BRCA2 mutations. Cancer Res, 2000. 60(2): p. 40916.

[27] Jones, S., et al., Exomic sequencing identifies PALB2 as a pancreatic cancer susceptibility gene. Science, 2009. 324(5924): p. 217.

[28] Tischkowitz, M.D., et al., Analysis of the gene coding for the BRCA2-interacting protein PALB2 in familial and sporadic pancreatic cancer. Gastroenterology, 2009. 137(3): p. 1183-6.

[29] Slater, E.P., et al., PALB2 mutations in European familial pancreatic cancer families.Clin Genet, 2010. 78(5): p. 490-4.

[30] Giardiello, F.M., et al., Very high risk of cancer in familial PeutzJeghers syndrome. Gastroenterology, 2000. 119(6): p. 1447-53.

[31] Rebours, V., et al., Risk of pancreatic adenocarcinoma in patients with hereditary pancreatitis: a national exhaustive series. Am J Gastroenterol, 2008.103(1): p. 111-9.

[32] Howes, N., et al., Clinical and genetic characteristics of hereditary pancreatitis in Europe. ClinGastroenterolHepatol, 2004 2(3): p. 252-61.

[33] Vymetalkova, V.P., et al., Molecular characteristics of mismatch repair genes in sporadic colorectal tumors in Czech patients. BMC Med Genet, 2014. 15: p. 17.

[34] Vasen, H.F., et al., Risk of developing pancreatic cancer in families with familial atypical multiple mole melanoma associated with a specific 19 deletion of p16 (p16-Leiden).Int J Cancer, 2000. 87(6): p. 809-11.

[35] Lundin, K.E. and L.M. Sollid, Advances in coeliac disease. CurrOpinGastroenterol, 2014. 30(2): p. 154-62. 